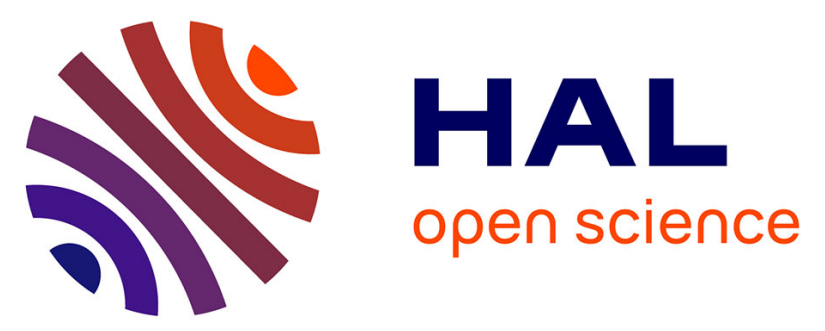

\title{
Investigation of oxygen disorder, thermal parameters, lattice vibrations and elastic constants of UO2 and ThO2 at temperatures up to $2930 \mathrm{~K}$
}

\author{
K. Clausen, W. Hayes, M. T. Hutchings, J.E. Macdonald, R. Osborn, P. \\ Schnabel
}

\section{To cite this version:}

K. Clausen, W. Hayes, M. T. Hutchings, J.E. Macdonald, R. Osborn, et al.. Investigation of oxygen disorder, thermal parameters, lattice vibrations and elastic constants of UO2 and ThO2 at temperatures up to $2930 \mathrm{~K}$. Revue de Physique Appliquée, 1984, 19 (9), pp.719-722. 10.1051/rphysap:01984001909071900 . jpa-00245244

\section{HAL Id: jpa-00245244 https://hal.science/jpa-00245244}

Submitted on 1 Jan 1984

HAL is a multi-disciplinary open access archive for the deposit and dissemination of scientific research documents, whether they are published or not. The documents may come from teaching and research institutions in France or abroad, or from public or private research centers.
L'archive ouverte pluridisciplinaire $\mathbf{H A L}$, est destinée au dépôt et à la diffusion de documents scientifiques de niveau recherche, publiés ou non, émanant des établissements d'enseignement et de recherche français ou étrangers, des laboratoires publics ou privés. 


\title{
Investigation of oxygen disorder, thermal parameters, lattice vibrations and elastic constants of $\mathrm{UO}_{2}$ and $\mathrm{ThO}_{2}$ at temperatures up to $2930 \mathrm{~K}$
}

\author{
K. Clausen $\left({ }^{+.1}\right)$, W. Hayes $\left({ }^{+}\right)$, M. T. Hutchings $(*)$, J. E. Macdonald $\left({ }^{+.2}\right)$, R. Osborn $\left({ }^{+}\right)$ \\ and P. Schnabel $\left({ }^{+.3}\right)$ \\ $\left(^{+}\right)$Clarendon Laboratory, Parks Road, Oxford, OX1 3PU, U.K. \\ $\left(^{*}\right)$ Materials Physics Division, AERE Harwell, Didcot, Oxon, OX11 0RA, U.K
}

\begin{abstract}
Résumé. - La connaissance des propriétés thermodynamiques de $\mathrm{UO}_{2}$ dans le domaine $1500-3100 \mathrm{~K}$ est d'une grande importance pour les calculs de sécurité nucléaire. Cependant, on ne dispose que de peu de résultats expérimentaux. En particulier, l'importante question de l'apparition du désordre de Frenkel à haute température n'avait pas encore été résolue. Les laboratoires de Harwell ont acquis un nouveau four pour cette gamme de températures; de nombreuses expériences ont été effectuées, en particulier diffraction, diffusion quasiélastique et diffusion inélastique des neutrons par des monocristaux de $\mathrm{UO}_{2}$ et $\mathrm{ThO}_{2}$. Celles-ci ont été complétées par des expériences réalisées à l'ILL dans la gamme de températures allant jusqu'à $2500 \mathrm{~K}$. Des détails du four et les méthodes de mesure de température et de montage des cristaux sont présentés ainsi que les principaux résultats. Pour la première fois, on montre que le désordre de type Frenkel apparaît dans $\mathrm{UO}_{2}$ au-dessus de $2000 \mathrm{~K}$.
\end{abstract}

\begin{abstract}
A knowledge of the thermodynamic properties of $\mathrm{UO}_{2}$ at temperatures in the region $1500-3100 \mathrm{~K}$ is of importance in reactor safety calculations, yet there are relatively few detailed experimental data available. In particular the major question of whether Frenkel disorder occurs in $\mathrm{UO}_{2}$ at high temperatures has been unanswered until now. A new high temperature furnace has been purchased by Harwell for work at temperatures in this region, and a series of experiments has been carried out involving diffraction, quasielastic diffuse and inelastic neutron scattering from single crystals of $\mathrm{UO}_{2}$ and $\mathrm{ThO}_{2}$. These have been backed by experiments in the lower temperature range to $2500 \mathrm{~K}$ at I.L.L. Details of the Harwell furnace, and methods used for temperature measurement and encapsulation of the crystal samples are given, together with some examples of the principal results. These results show unambiguously, for the first time, that oxygen Frenkel disorder does occur in $\mathrm{UO}_{2}$ above $2000 \mathrm{~K}$.
\end{abstract}

\section{Introduction.}

Uranium dioxide, $\mathrm{UO}_{2}$, exhibits an anomalous specific heat, $C_{\mathrm{p}}$, or enthalpy, $H$, above $\sim 1500 \mathrm{~K}$ which cannot be accounted for by the usual contributions of harmonic and anharmonic lattice vibrations and dilation [1]. The exponential rise above $1500 \mathrm{~K}$ indicates that additional excitation or activation processes occur in $\mathrm{UO}_{2}$. Excitation of crystal field levels of the $\mathrm{U}^{4+}$ ion [1], together with ẹther the creation of Frenkel defects in the oxygen sublattice

( $\left.{ }^{1}\right)$ Present address : Department of Physics, Ris $\phi$ National Laboratory, DK-4000 Roskilde, Denmark.

$\left({ }^{2}\right)$ Present Address : School of Physics, University of Bath, Bath, BA2 7AY, U.K.

$\left({ }^{3}\right)$ Present Address : ESAMS Ltd., Lyon Way, Camberley, GU16 5EX, U.K.
[2-4], or the creation of electronic disorder of the small polaron type, represented by $2 \mathrm{U}^{4+} \leftrightarrows \mathrm{U}^{5+}+\mathrm{U}^{3+}[5-$ 7], have been suggested as the principal contributions. However, several recent analyses of enthalpy data come to different conclusions as to which is the main cause of the anomaly $[8,9]$, and the relative contribution of Frenkel and electronic disorder is not unambiguously established. Furthermore there has been little information on the lattice dynamics of $\mathrm{UO}_{2}$ at elevated temperatures, which has hindered the interpretation of thermal conductivity as well as enthalpy data [10]. A thorough understanding of these thermophysical properties of $\mathrm{UO}_{2}$ is necessary for realistic reactor safety calculations.

In this paper we describe the use of neutron scattering techniques to investigate the possible occurrence of Frenkel disorder in $\mathrm{UO}_{2}$, and to investigate the lattice dynamics of $\mathrm{UO}_{2}$ [11], at temperatures up 
to $2930 \mathrm{~K}$, the highest temperatures yet attained in neutron scattering measurements. The melting temperature of $\mathrm{UO}_{2}$ is $T_{\mathrm{m}}=3120 \mathrm{~K}$. Parallel work is being carried out on $\mathrm{ThO}_{2}\left(T_{\mathrm{m}}=3640 \mathrm{~K}\right)$ since in this case no small polaron formation is expected because of the stability of the $\mathrm{Th}^{4+}$ valence. The techniques and the interpretation of the data which we have adopted are the same as those used in our recent investigation [13-15] of the isostructural halide fluorites $\mathrm{PbF}_{2}, \mathrm{SrCl}_{2}$ and $\mathrm{CaF}_{2}$ with $T_{\mathrm{m}}=1128$, 1146 and $1696 \mathrm{~K}$ respectively. The much higher temperatures involved in a study of $\mathrm{UO}_{2}$ have necessitated the use of a new high temperature furnace specially constructed for neutron scattering studies and this will be described together with the high temperature techniques used in the next section. The ability of neutrons to penetrate the metal walls of heater elements, heat shields, and sample containment tubes, makes them a unique scattering probe of samples at very high temperatures. The measurements are described in section 3 together with a brief summary of the results and the conclusions are given in section 4 .

\section{Experimental techniques.}

Most of the experiments described here were carried out at Harwell using a new high temperature furnace specially designed and constructed to our specifications by D. Hukin of Crystalox Ltd., Wantage, U.K. A diagram of the main features is shown in figure 1.

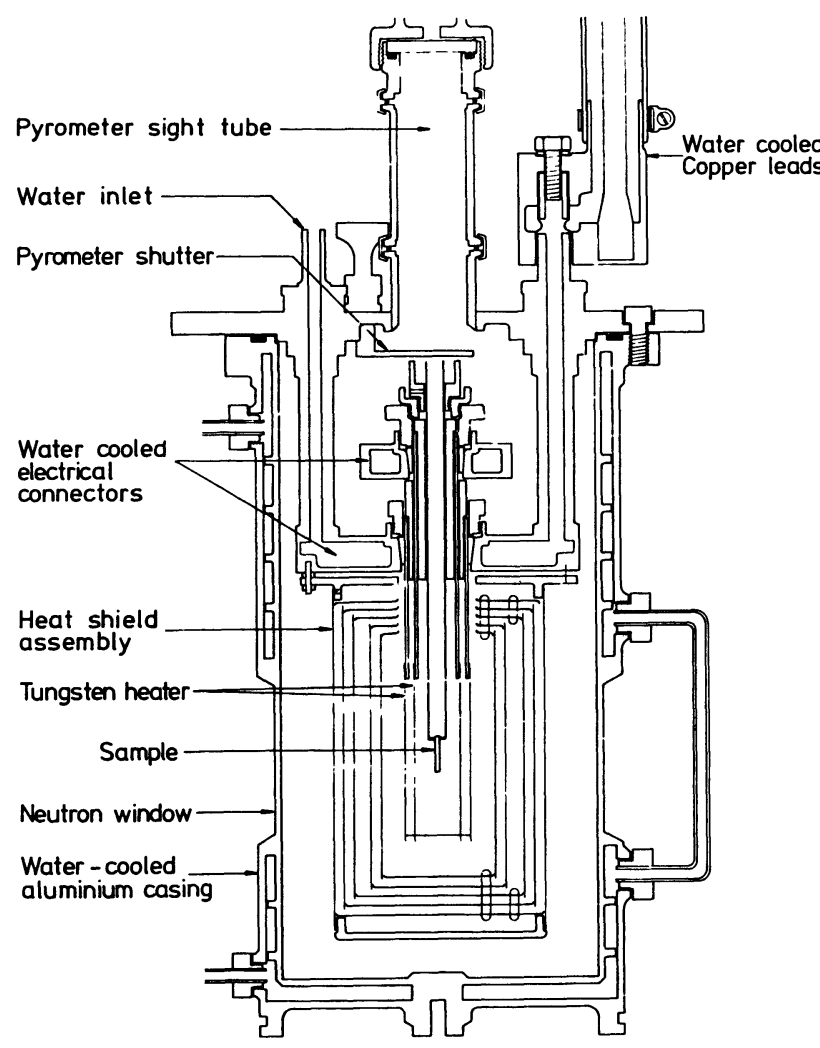

Fig. 1. - Schematic diagram of the Harwell high temperature furnace.
Since most refractory metals have appreciable neutron absorption, a careful balance must be reached in the design of heater element and heat shields between their absorption and their finite lifetime due to evaporation at the highest temperatures. Furthermore a large number of heat shields are necessary to reduce radiation losses which dominate the heat loss above $2300 \mathrm{~K}$. Care must also be taken so that adjacent materials are not prone to high reactivity at high temperatures. Most metals soften well below their melting point, and some, such as tantalum, have a tendency to recrystallise at high temperatures. These considerations have led us to use tungsten for the components which are subjected to the highest temperatures : heater element, inner heat shields, and sample support and encapsulating tubes. As seen from figure 1 the basic design is fairly conventional but the principal feature is Hukin's novel heater element which consists of two concentric tungsten tubes, of diameters $25 \mathrm{~mm}$ and $35 \mathrm{~mm}$ and thickness $0.25 \mathrm{~mm}$ and $0.40 \mathrm{~mm}$ respectively, joined at their lower end by an annular tungsten ring and centre disc. They are welded at the top to two concentric thickwalled tantalum tube electrodes. These two electrodes are attached via phosphor bronze collars, which provide good electrical and thermal conductivity and accurate alignment, to water cooled conductors which pass through the steel top plate of the furnace. The thyristor power supply, in the phase-angle mode, is fed through water-cooled copper leads from the transformer of the power supply. This design of heater gives good uniformity of temperature over the length of a $3 \mathrm{~cm}$ sample, and ensures low radiation losses from the inner conductor.

The heat shield assembly detaches as one unit and consists of two inner tungsten and three outer molybdenum shields. The inner and outer shield are $0.25 \mathrm{~mm}$ thick and the others $0.12 \mathrm{~mm}$ thick. A further molybdenum shield is positioned just inside the aluminium water-cooled vacuum chamber. The overall transmission of neutrons at $2.3 \AA$ is $\sim 65 \%$ and the viewing angle is approx. $300^{\circ}$. Depending on the method of temperature measurement to be used, the sample is suspended from the top, low temperature, region on either a tungsten rod or tungsten tube. In the latter case a thin molybdenum sleeve onto which grub screws can grip is welded to the tube. The samples are sealed, by electron beam welding under vacuum, in tungsten tubes. These are coated with tantalum nitride to reduce the reactivity with the oxide under investigation. The method of attaching the sample tube to the suspension tube has evolved during the experiments, the most satisfactory method being to seal the sample tube with a lid in the form of a collar to which the suspension tube is spot welded. Boron nitride spacers are used to keep the suspension tube or rod concentric in the furnace, and to separate the tantalum heater electrodes. These help to reduce heat loss upwards. 
The temperature is measured either by a tungsten/ tungsten $26 \%$ rhenium thermocouple, with the hot junction welded to the top of the sample tube, or by a Land, silicon-sensor, infra-red pyrometer. The former is used for temperatures up to $\sim 2473 \mathrm{~K}$, and the latter for temperatures above $2273 \mathrm{~K}$. The pyrometer is adjusted to view the top of the sample tube down the suspension tube, and a closed shutter is usually placed in the sight line to reduce radiation losses when not measuring the temperature. An important check on the temperature measurement is the lattice constant of the sample under study, or that of the encapsulating tungsten tube.

The furnace is usually operated with an internal overpressure of carefully dried argon gas in order to minimise evaporation of the heater element. Typical operating conditions at $2523 \mathrm{~K}$ are $900 \mathrm{amps}$ in the secondary, with approximately half the $8 \mathrm{~kW}$ dissipated in the leads and half in the heater. The temperature is controlled by stabilization of the input power to the output transformer, and this has proved very satisfactory. It may be increased or decreased automatically by a motorised ramping control.

Demineralised water is used for the cooling system which flows around a closed circuit at $\sim 17 \mathrm{ltr} / \mathrm{min}$, shared between the leads and the outer furnace casing. The input temperature is kept at $10^{\circ} \mathrm{C}$ by a $\mathrm{F}$ and $\mathrm{R}$ water chiller. A series of temperature and flowmeter trips in the water circuit, and a current limiter, protect the furnace from overheating.

The furnace has operated successfully for several days at its present maximum temperature, $2930 \mathrm{~K}$, providing data at the highest temperature yet attained in a neutron scattering experiment. The heater elements usually last for one to two weeks when operating at $2673 \mathrm{~K}$ and above.

\section{Measurements and results.}

Five samples of $\mathrm{UO}_{2}$, and three of $\mathrm{ThO}_{2}$, were investigated in separate experiments using the Mk VI diffractometer in the DIDO reactor, Harwell, with incident wavelength $1.092 \AA$. All the $\mathrm{UO}_{2}$ samples were cut in cylindrical shape, $\sim 1.6 \mathrm{~mm}$ diameter and $4 \mathrm{~mm}$ long, from boules supplied by Degussa A. G., and were reduced for several hours in hydrogen at $1773 \mathrm{~K}$ to ensure stoichiometry. The $\mathrm{ThO}_{2}$ samples were cut from flux grown crystals prepared by B. Wanklyn and B. Garrard at the Clarendon Laboratory, Oxford. The diffraction data on both samples were interpreted, after correction for extinction, thermal diffuse scattering and evaporation loss, in the same manner as that used in a study of Frenkel disorder in $\mathrm{PbF}_{2}$ [13]. The time-averaged disorder structure was modelled in terms of a fraction, $n_{\mathrm{d}}$, of anions leaving their regular sites to occupy either or both of two sites in the " empty " anion cubes of the fluorite structure $[13,16]$. The best model was judged as that giving the lowest weighted $R$-factor in a least squares fit to the data. As well as $n_{\mathrm{d}}$, isotropic temperature factors were determined at each temperature for the cation and the anion in regular and defect sites, together with an anisotropic temperature factor for the regular anion site and two parameters determining the location of the defect sites. At the highest temperatures the best fits were given by a model for which the relative population of the two sites corresponded to the formation of simple $3: 1: 2$ clusters, where the ratios denote numbers of vacancy : interstitial : relaxed anions, comprising a Frenkel pair with the two nearest-neighbours of the oxygen interstitial relaxed into the adjacent empty cubes [15]. The values of $n_{\mathrm{d}}$ determined from the fits to the data were found to be fairly independent of the particular model chosen. Those found from the best fitting models for $\mathrm{UO}_{2}$ and $\mathrm{ThO}_{2}$ are plotted in figures 2 and 3 where

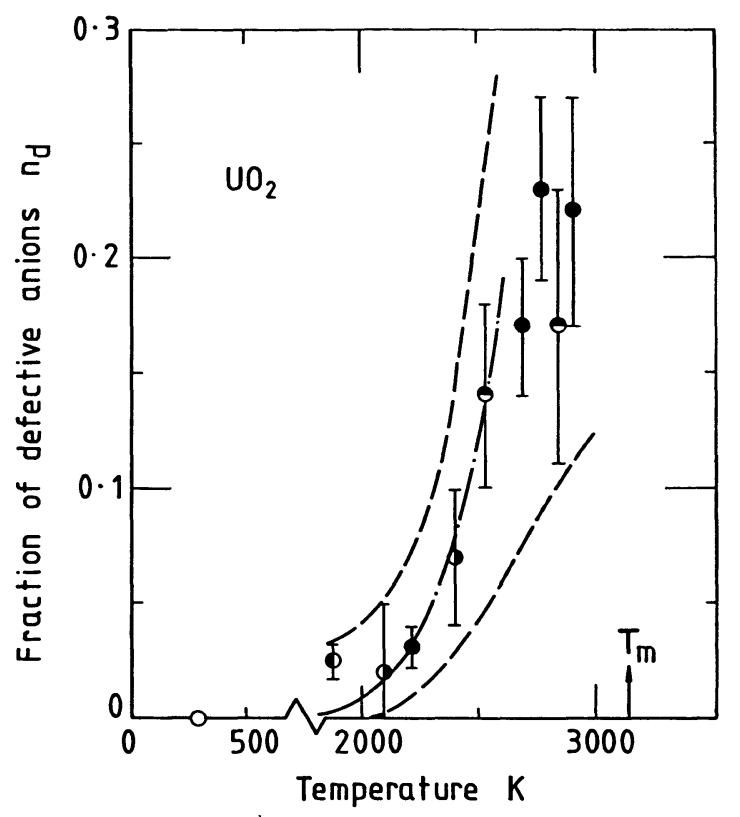

Fig. 2. - Temperature variation of $n_{\mathrm{d}}$, the fraction of oxygen ions leaving their regular sites in $\mathrm{UO}_{2}$. The broken lines are described in the text. Different symbols correspond to data from different samples.

it is seen that Frenkel disorder does occur above $2000 \mathrm{~K}$, and increases with temperature increase. Using the $3: 1: 2$ cluster model the number of Frenkel pairs $n_{\mathrm{f}}=n_{\mathrm{d}} / 3$. The dash-dot lines in figures 2 and 3 represent exponential increases with Frenkel pair formation energies of 4.6 and $5.4 \mathrm{eV}$ respectively. The value for $\mathrm{UO}_{2}$ with error $\sim 0.5 \mathrm{eV}$, is found from fitting to the data. However, in the case of $\mathrm{ThO}_{2}$ the data are insufficient to enable a unique fit to be made, and the value used is that found for $\mathrm{UO}_{2}$ scaled by the melting temperatures. Details of the variation of the temperature factors with temperature will be reported elsewhere [17].

Further evidence for oxygen-ion disorder in $\mathrm{UO}_{2}$ comes from the observation of diffuse scattering along [100] beyond the (200) reciprocal lattice point 


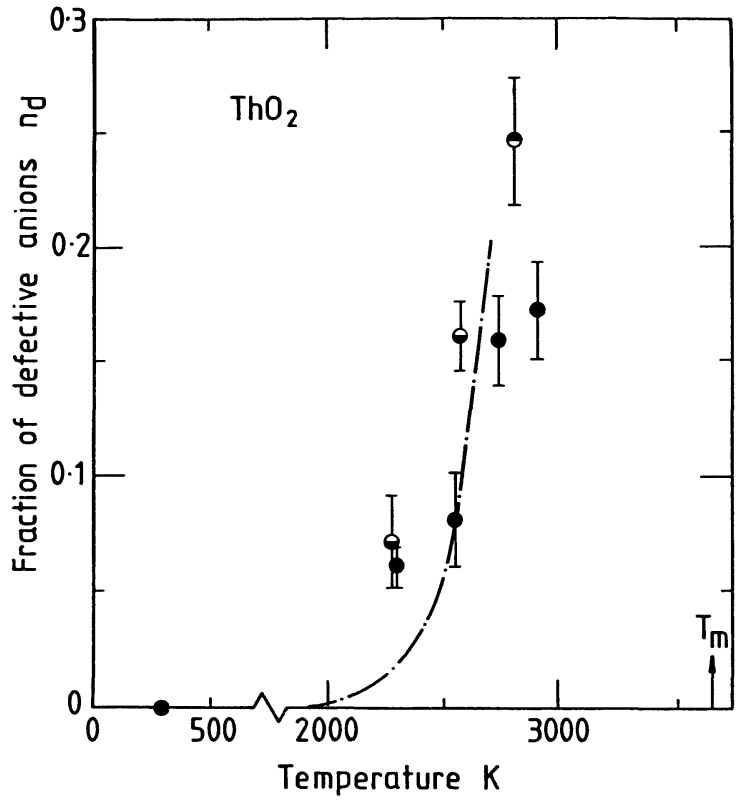

Fig. 3. - Temperature variation of $n_{\mathrm{d}}$ in $\mathrm{ThO}_{2}$.

[16], similar to that observed in the halide fluorites [14, 15]. These measurements were made using the tripleaxis spectrometer in the PLUTO reactor, Harwell. A quantitative estimate of $n_{\mathrm{d}}$ may also be made from this diffuse scattering, and though less accurate this leads to estimates which lie between the dashed lines in figure 1 , in very reasonable agreement with the diffraction data.

The temperature variation of the phonons have also been studied in $\mathrm{UO}_{2}$ using the PLUTO tripleaxis spectrometer following earlier work carried out at Ris $\emptyset$ National Laboratory [18]. Those optic modes investigated are found to broaden rapidly in the region of $2200 \mathrm{~K}$ and become unobservable at higher temperatures. The acoustic modes however are well defined to $2930 \mathrm{~K}$, although they broaden as the temperature is increased above $2000 \mathrm{~K}$. They have been measured in the symmetry directions as a function of temperature enabling the three elastic constants and hence the bulk modulus to be determined to $2930 \mathrm{~K}$. These data will be reported in detail in a future paper [17]. In most respects the scattering from lattice vibrations in $\mathrm{UO}_{2}$ resembles that from $\mathrm{PbF}_{2}$ as the temperature is raised into the fast ion regime.

\section{Conclusions.}

The neutron diffraction, diffuse scattering and inelastic scattering from $\mathrm{UO}_{2}$, and the diffraction from $\mathrm{ThO}_{2}$ have been investigated to $2930 \mathrm{~K}$ using a new, unique, high temperature furnace specially designed for neutron scattering work. The data show unambiguously, for the first time, that Frenkel disorder does occur in both compounds, and in most respects the results obtained so far at high temperature resemble the scattering from the halide fluorites in the fast-ion phase. We have not yet observed scattering which might indicate small polaron formation, evidence for which can only be obtained indirectly, but further experiments to search for this are currently planned.

\section{Acknowledgments.}

We wish to thank D. Hukin for advice and discussions on high temperature technology, and P. Bowen and W. Futcher for experimental assistance. This work has been supported by the U.K.S.E.R.C., A.E.R.E. Harwell, NATO Research Grant No. 1806, and the Danish Natural Science Research Council.

\section{References}

[1] Browning, P., J. Nucl. Mater. 98 (1981) 345-356, and references therein.

[2] BrediG, M., Colloques Int. C.N.R.S. No. 105 (1972) 183-191.

[3] Szwarc, R., J. Phys. Chem. Solids 30 (1969) 705-711.

[4] Matzke, H. J., Plutonium and other actinides, eds. Blank, H. and Lindner, R. (North Holland : Amsterdam) 1976, p. 801-831.

[5] Macinnes, D. A., Proc. Intl. Symp. on Thermodynamics of Nuclear Materials, Julich, FRG 1979 (Vienna : IAEA) 1979, 129-139, and J. Nucl. Mater. 78 (1978) 225-227.

[6] Harding, J. H., Masri, P. and Stoneham, A. M. J. Nucl. Mater. 92 (1980) 73-78.

[7] Hyland, G. J. and RalPH, J., High TemperaturesHigh Pressures 15 (1983) 179-190.

[8] Browning, P., Hyland, G. J. and Ralph, J., High Temp.-High Pressures 15 (1983) 169-178.

[9] Fink, J. K., Int. J. Thermophys. 3 (1982) 165-200.

[10] Hyland, G. J., J. Nucl. Mater. 113 (1983) 125-132.

[11] Dolling, G., Cowley, R. A. and Woods, A. D. B., Can. J. Phys. 43 (1965) 1397-1413.

[12] Fischer, D. H., Fink, J. K. and Leibowitz, L. J., Nucl. Mater. 102 (1981) 220-222.
[13] Dickens, M. H., Hayes, W., Hutchings, M. T. and Smith, C., J. Phys. C 15 (1982) 4043-4060.

[14] Clausen, K., Hayes, W., Hutchings, M. T., Kuems, J. K., Schnabel, P. and Smith, C., Solid State Ionics 5 (1981) 589-592.

[15] Hutchings, M. T., Clausen, K., Dickens, M. H., Hayes, W., KJems, J. K., Schnabel, P. and SMITH, C., AERE Harwell Report R-11127 (1984) and $J$. Phys. $C$ (to be published).

[16] Clausen, K., Hayes, W., Hutchings, M. T., MacDONAld, J. E. and Osborn, R., Phys. Rev. Lett. 52 (1984) 1238-1241.

Clausen, K., Hayes, W., Hutchings, M. T., KJems, J. K., Macdonald, J. E. and OsboRn, R., High Temp. Sci. (to be published).

[17] Hutchings, M. T., Clausen, K., Hayes, W., MaCDONAld, J. E., Osborn, R. and Schnabel, P., High Temp. Phys. (to be published).

[18] Clausen, K., Hayes, W., Hutchings, M. T., KJems, J. K., Macdonald, J. E. and Schnabel, P., High Temperatures-High Pressures 15 (1983) 383390. 